\title{
Production of Planktonic and Non-planktonic Larvae in a Single Brood of Capitella sp. I and its Implications for Population Persistence in Disturbed Environment due to Organic Enrichment of the Sediments
}

\author{
Hiroaki Tsutsumi \\ Faculty of Environmental and Symbiotic Sciences, Prefectural University of Kumamoto, \\ 3-1-100 Tsukide, Kumamoto 862-8502, Japan
}

\begin{abstract}
We observed that a small number of embryos in brood tubes of the lecithotrophic capitellid, Capitella sp. I, remained and metamorphosed into crawl-away juveniles in the parental brood tube after the parent and other larvae had left. In order to investigate whether this behavior might have a genetic basis, we reared the planktonic and non-planktonic individuals separately in population cages for three consecutive generations. In each generation, three food levels were used, producing mature worms of different sizes. Food supply appeared to have no direct effect on the number of non-planktonic larvae per first brood produced. Brood size ranged from 3 to 371 embryos per brood tube over the different food treatments, and was closely correlated with the size of the female parent. We found 2 to 8 non-planktonic individuals per brood irrespective of brood size. High proportions of non-planktonic larvae per brood $(>20 \%)$ were only found in the smallest broods ( $<50$ embryos per brood). In all broods with $>100$ embryos, $>95 \%$ of the individuals were planktonic. Since the proportion of non-planktonic individuals did not increase with short-term selection for this trait over two generations, we concluded that it does not have a genetic basis. Nevertheless, the small number of non-planktonic individuals in this lecithotrophic species may be important over relatively small scales (on the order of $100 \mathrm{~m}$ ) in the recovery of relict populations decimated by the hypoxic conditions which often develop in organically enriched sediments.
\end{abstract}

Key words: Capitella sp. I, non-planktonic larvae, organic enrichment, phenotypic plasticity, plakntonic larvae, poecilogony, reproductive strategy

\section{INTRODUCTION}

Some marine invertebrate species produce more than one kind of larva and are said to be poecilogonous (Hoagland \& Robertson 1988; Levin \& Bridges 1994; Gibson \& Chia 1995; Chia et al. 1996; Gibson 1997). One of the best studied examples among the polychaetes is Streblospio benedicti, whose planktotrophic and lecithotrophic larvae have been examined both in the field and in the laboratory by Levin and her colleagues (Levin \& Creed 1986; Levin et al. 1991; Levin \& Bridges 1994). Hybridization of planktotrophic and lecithotrophic morphs produces intermediate individuals, which also occur in the field, where the two extreme types often coexist. An

Received April 16,, 2005: Accepted June 20, 2005 analysis of the mechanisms maintaining this polymorphism suggests that they involve both genetic and environmental factors, and their interaction.

In a deposit feeding polychaete, Capitella capitata, which often occurs densely in disturbed environment due to organic enrichment of the sediment (Pearson \& Rosenberg 1978), Forét (1974) reported the production of two different larvae, planktonic larvae and benthic larvae with no planktonic stage from a population of this species. This finding suggested the presence of poecilogony in Capitella capitata. However, Grassle \& Grassle (1976) found the presence of many genetically distinct sibling species in a single species of Capitella capitata defined by the adult morphology, which do not interbreed, and possess different larval developmental patterns and morphology. These sibling species have either direct, planktotrophic, or lecithotrophic modes of development (Grassle 1980). Others (e.g., Qian \& Chia 1993) 
may indeed provide evidence of an undescribed poecilogonous species in this genus, but further investigation is needed to confirm such reports.

We have studied the population dynamics of Capitella sp. I (sensu Grassle \& Grassle 1976) in the field for two decades (Tsutsumi \& Kikuchi 1983, 1984; Tsutsumi 1987, 1990) and were struck by the ability of this lecithotrophic species to rapidly recolonize habitats where populations had previously been extirpated by hypoxic conditions, albeit over small spatial scales on the order of $100 \mathrm{~m}$. In the course of carrying out laboratory experiments on Capitella sp. I population dynamics (Tsutsumi \& Kikuchi 1984; Tsutsumi et al. 1990), we noted that in many Capitella sp. I brood tubes a few normally developing embryos did not hatch and swim freely in the water. Rather, after developing to the metatrochophore stage (Eckelbarger \& Grassle 1987), when they could be seen swimming vigorously within the membranes of the parental brood tube, they remained in the brood tube even after the parent had crawled away, and most of the other larvae were swimming in the overlying water. They went on to metamorphose within the brood tube and to crawl away as juveniles. While there was no evidence for any differences in morphology, egg size and developmental process like the poecilogonous species, except the hatching behavior between these "planktonic" and "non-planktonic" individuals, we reasoned that this behavior could be important in re-establishing small relict populations following their near-elimination due to adverse environmental conditions.

In the present study, we examined whether we could select for this non-pelagic trait as a genetically fixed characteristics, by cross-breeding individuals derived from planktonic and non-planktonic parents isolated at hatching from brood tubes of worms collected in the field. We performed this experiment for two consecutive generations in the laboratory. In both generations, worms were kept in population cages at different food levels. But, since these food levels affected only worm size and not the trait of interest, we pooled the worms from the different treatments in each generation. With the results of this study, we discussed the adaptive meanings of the production of planktonic and non-planktonic larvae from a single brood of Capitella sp. I.

\section{MATERIALS AND METHODS}

Fig. 1 shows the process of the experiment to examine the ratios of planktonic and non-planktonic larvae in a brood tube of worms collected from the field and two consecutive generations in the laboratory (Fig. 1).

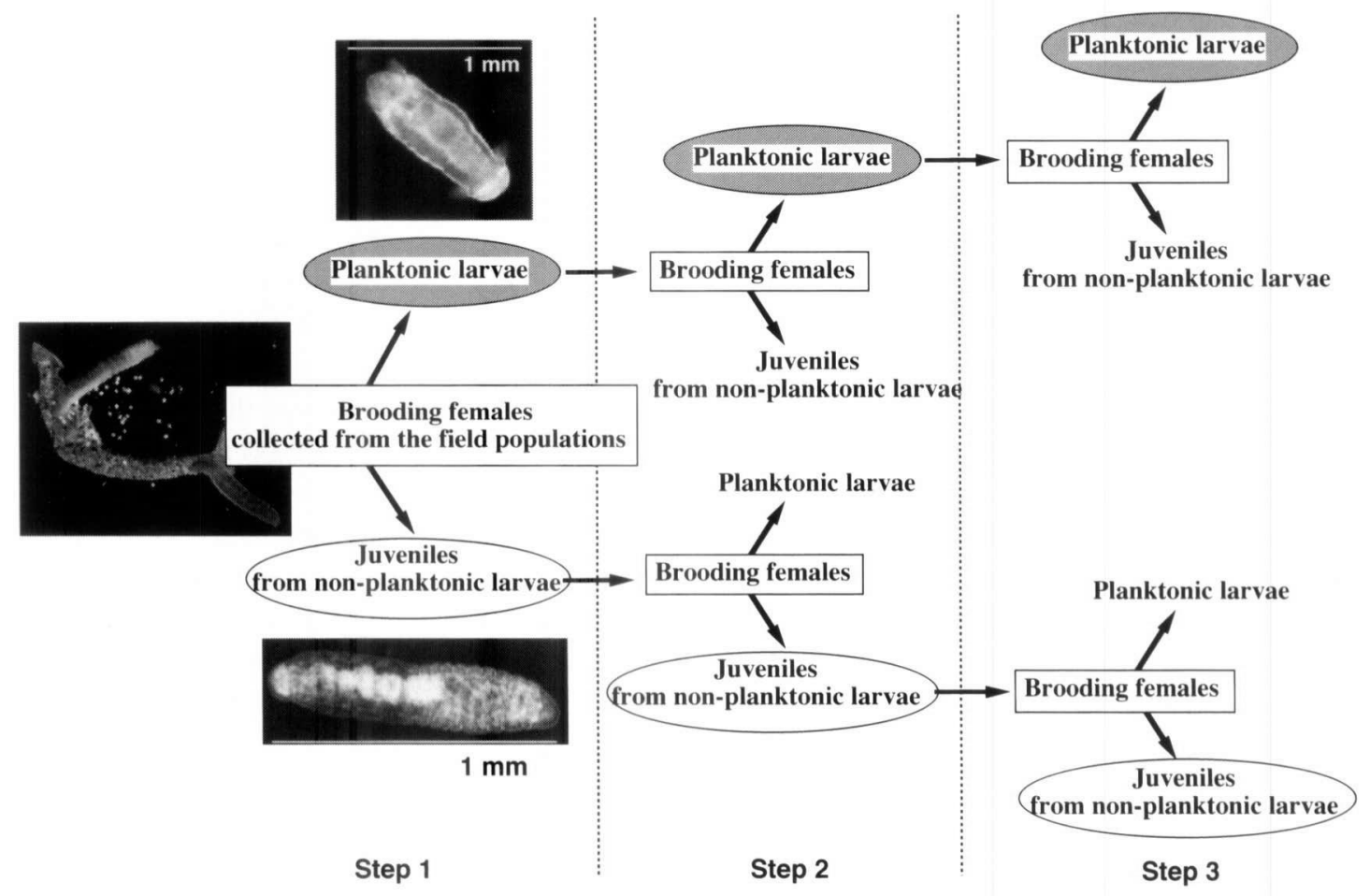

Fig. 1. The process of the experiment to examine the ratios of planktonic and non-planktonic larvae in a brood tube of worms collected from the field and two consecutive generations in the laboratory. 
Step 1: ratios of "planktonic" and "non-planktonic" larvae in a brood tube of worms collected in the field

We collected brood tubes of Capitella females from sandbanks with approximately $1,000 \mathrm{~m}^{2}$ of the river mouth of Kotsuki River, Kagoshima, Kyushu, Japan $\left(31^{\circ} 35^{\prime} \mathrm{N}, 130^{\circ} 34^{\prime} \mathrm{E}\right)$ in May 1995 , isolated them in the petri dishes with sea water under room temperature $(15$ to $25^{\circ} \mathrm{C}$ ), and checked the Petri dishes twice a day. Within a week, all of the larvae hatched out from the brood tubes. When we found "planktonic larvae" that were swimming in the water in the petri dishes or metamorphosed juveniles from "non-planktonic larva" that were crawling on the bottom of the petri dishes, we collected them separately and counted their numbers. After all of the larvae had left the brood tubes, we collected the females, fixed with $10 \%$ formalin solution, and measured their body sizes with a stereoscopic microscope image analyzing system (stereoscopic microscope, OLYMPUS SMZ-10; CCD camera, SONY DXY-630; computer, Apple Macintosh Quadra 700; Frame Grabber, Data Translation Quick Capture, software NIH Image Ver. 1.60).

This Capitella species was identified as "Capitella sp. I" by cross-breeding test with the laboratory colonies collected from Tomoe Cove, Amakusa, Kumamoto, Japan, which was identified by cross-breeding test with the original "Capitella sp. I" collected from the east coast of U.S. by J. P. Grassle (cf. Grassle \& Grassle 1976; Grassle 1980).

Step 2: ratios of "planktonic" and "non-planktonic" larvae in a brood tube of worms in the first generation of laboratory colonies

We collected 1,500 individuals of planktonic larvae and juveniles from non-planktonic larvae, respectively, in Step 1 of the experiment. We established three laboratory colonies with 500 individuals each in plastic containers $(20 \times 0 \times 10 \mathrm{~cm})$ with sediment and sea water. The containers with the Capitella colonies were kept in a chamber at $20^{\circ} \mathrm{C}$, being gently aerated in the water. We reared the three colonies from each of the planktonic and nonplanktonic larvae in three different nutritional conditions, providing three different amounts $(0.1,0.2$ and $0.3 \mathrm{~g})$ of ground fish pellets as food. Four weeks later, the sediment of each container was sieved with a $1.0 \mathrm{~mm}$ opening mesh, and 20 brood tubes of females were collected. These brood tubes were isolated in the petri dishes. In the same manner as in Step 1 of the experiment, we checked the petri dishes twice in a day, collected the planktonic

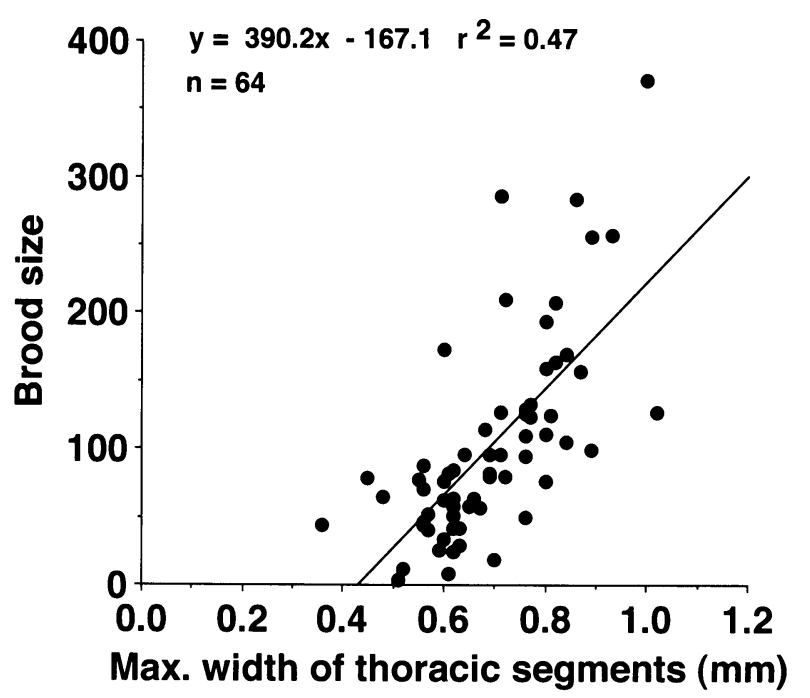

Fig. 2. The relationship between body size of brooding female and brood size at Step 1 of the experiment.

larvae and the juveniles from the non-planktonic larvae, and counted their numbers. The females were fixed with $10 \%$ formalin solution and we measured their body sizes.

\section{Step 3: ratios of "planktonic" and "non-planktonic" larvae in a brood tube of worms in the second genera- tion of laboratory colonies}

To confirm the results of Step 2 of the experiment, we repeated the experiments in the same ways with 1,500 individuals of planktonic larvae and juveniles from nonplanktonic larvae collected from Step 2 of the experiment.

\section{RESULTS}

The brood size increased with the body size of brooding female. Fig. 2 shows a significant positive correlation between these variables $\left(r^{2}=0.47, p<0.05\right.$, Pearson's correlation coefficient) at Step 1 of the experiment. The brood sizes varied from 3 to 371 in the range of the body sizes of brooding females between 0.36 and $1.02 \mathrm{~mm}$ in maximum width of thoracic segments. Fig. 3 shows the relationship between brood size and ratio of non-planktonic larvae in a brood in these broods. There was a clear tendency that high ratios of non-planktonic larvae from $23 \%$ to $96 \%$ were found only among the broods with less than 64 eggs. The mean ratios of non-planktonic larvae in a brood were calculated at intervals of 50 brood size (Fig. 4). The mean ratios of less than 50 eggs and 50 to less than 100 eggs reached 20.8 and $11.2 \%$ respectively, while those of the brood size classes of more than 100 


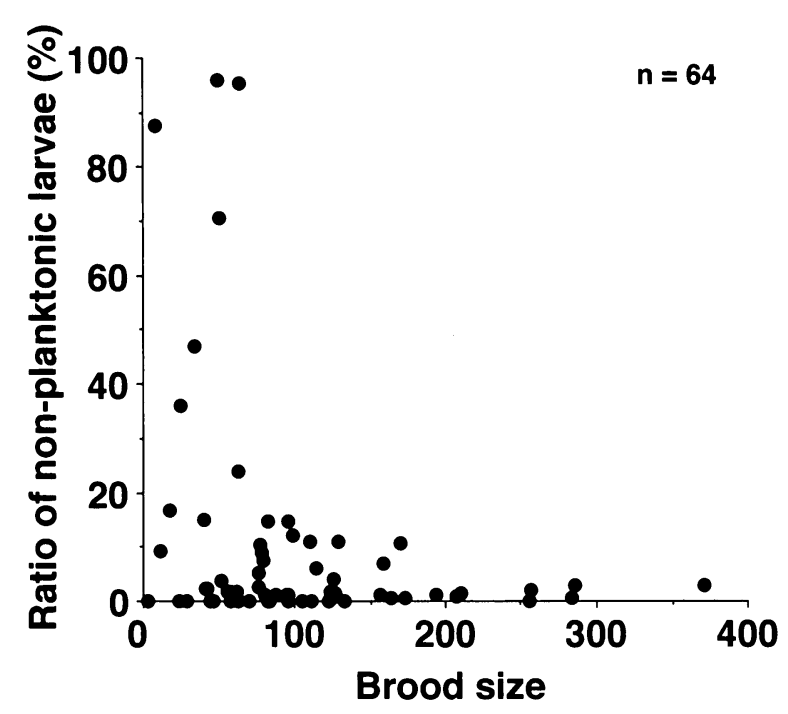

Fig. 3. The relationship between brood size and ratio of nonplanktonic larvae in a brood at Step 1 of the experiment.

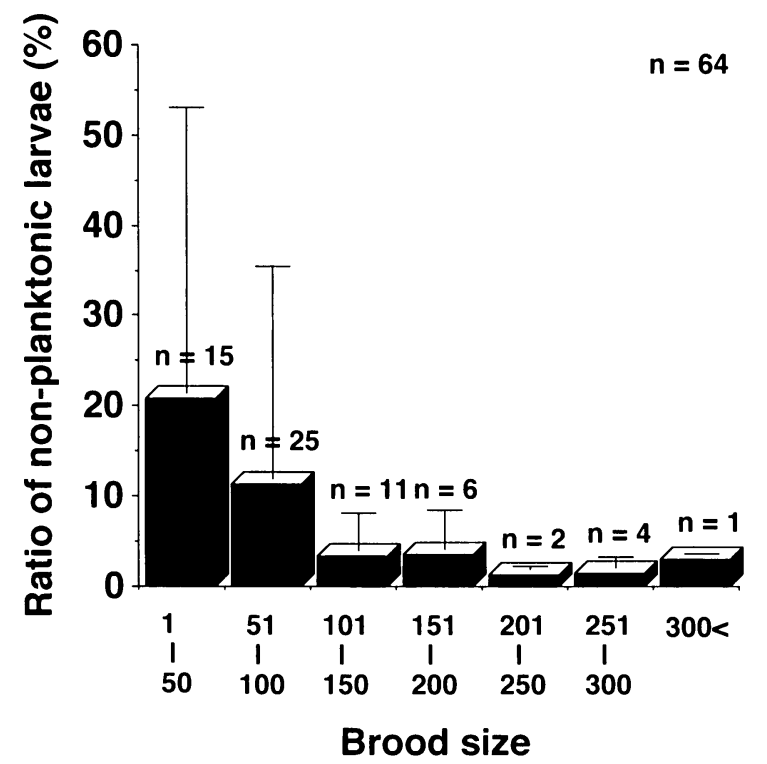

Fig. 4. Mean ratios of non-planktonic larvae in a brood at intervals of 50 brood size at Step 1 of the experiment.

eggs were less than $3.5 \%$. These differences of the mean ratios of non-planktonic larvae between the brood sizes of less than 100 and more than 100 eggs were, however, not statistically significant (Kruskal-Wallis test, $p>0.05$ ), due to too large deviations of the ratios in the brood size classes of less than 100 eggs.

Fig. 5 illustrates the mean numbers of these two types of larvae that were produced from a single brood at each brood size class of 50 eggs. The mean number of non-planktonic larvae varied in a narrow range between 2.5 and 7.4 individuals throughout the brood size classes. Those of planktonic larvae contrastively increased with the brood sizes from 24.5 individuals in the brood size

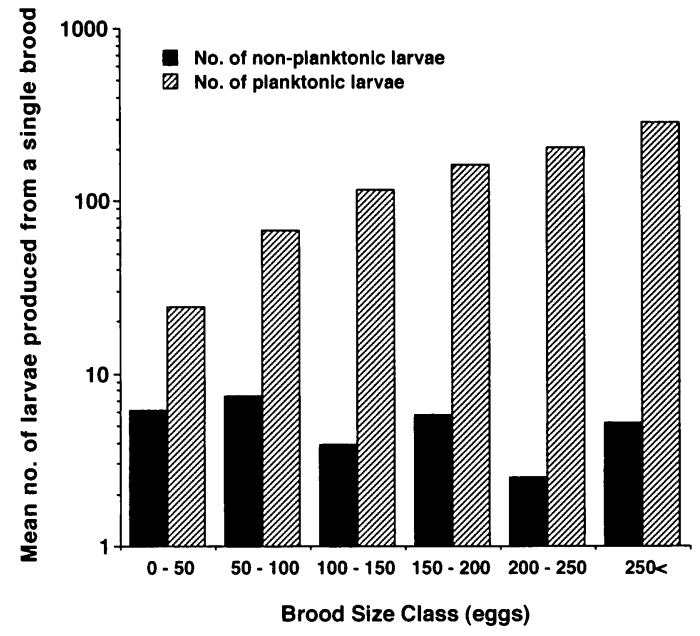

Fig. 5. Mean numbers of planktonic and non-planktonic larvae in a brood at intervals of 50 brood size at Step 1 of the experiment.

class of less than 50 eggs to 285.4 individuals in the brood size class of more than 250 eggs. Therefore, each female of Capitella sp. I allocates its reproductive materials for production of approximately 3 to 8 individuals of non-planktonic larvae in a brood, irrespective of its potential for reproductive output. The remaining portion of the brood is spent for production of planktonic larvae.

As mechanisms controlling the ratios of planktonic and non-planktonic larvae in a brood of females, here we can hypothesize two major factors. One is nutritional conditions that influence the growth of females since the brood size significantly correlates with the body size of female, and the other is the presence of two different genetic races with different growth schedules of larvae.

To confirm the hypotheses, we examined the ratios of planktonic and non-planktonic larvae in a brood in the broods of females that grew from each of planktonic and non-planktonic larvae at Steps 2 and 3 of the experiment. As shown in Fig. 6, there were very similar tendencies to the results of the Step 1 experiment in the relationship between brood size and ratios of non-planktonic larvae in a brood tube at these two steps, irrespective of the larval hatching behaviors that the females experienced. Higher ratios of non-planktonic larvae in a brood over 20-100\% were found in the broods with eggs numbering of less than 210 .

Fig. 7(a) shows the mean ratios of non-planktonic larvae in a brood at intervals of 50 brood sizes in the broods of females that grew from planktonic larvae in Step 3 of the experiment. The mean ratios of non-planktonic larvae in a brood reached $25.2 \%$ and $11.5 \%$ in the smallest brood groups of less than 50 eggs and 50 to 99 eggs, respectively, while only $1.9 \%$ of non-planktonic 
(a)

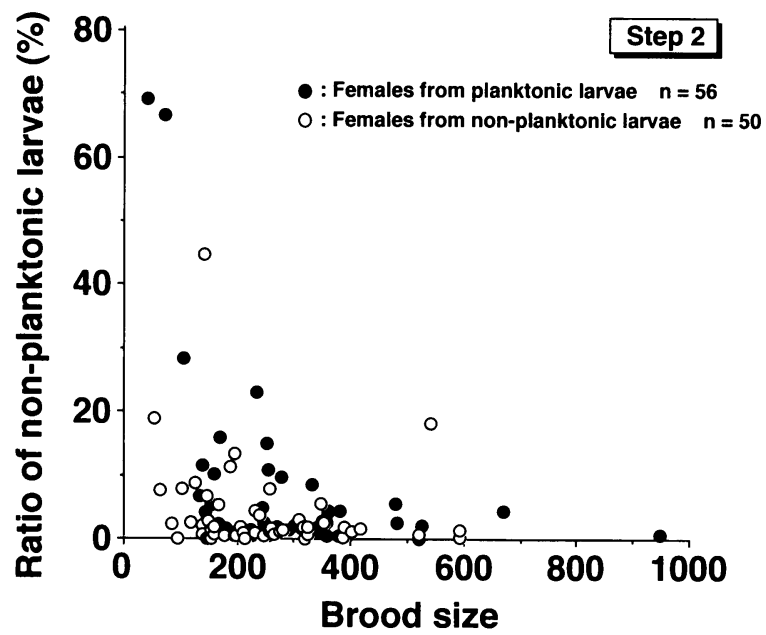

(b)

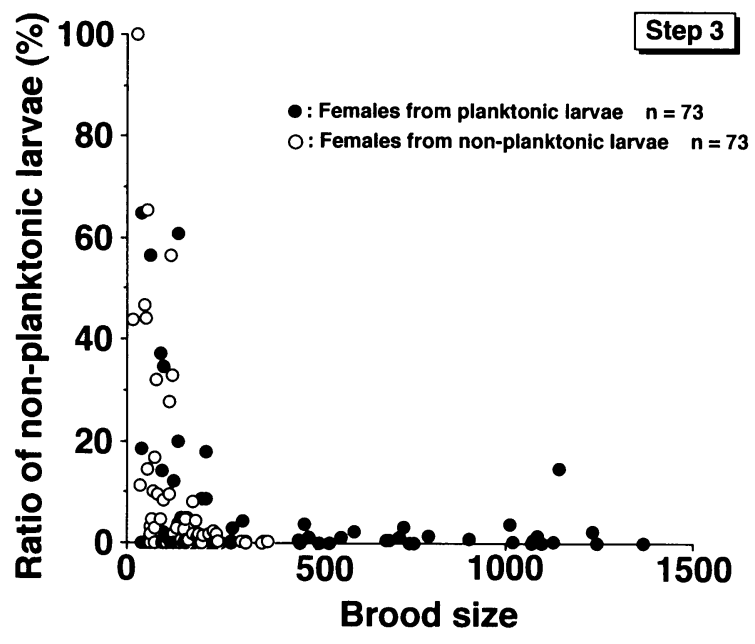

Fig. 6. The relationship between brood size and ratio of nonplanktonic larvae in a brood at (a) Step 2 and (b) Step 3 of the experiment.

larvae were contained in the large broods over 150 eggs. No statistical significance was found in the ratios of nonplanktonic larvae in a brood between the brood of less than 100 eggs and more than 150 eggs (KruskalWallis test, $p>0.05$ ). Very similar results were found from the mean ratios of non-planktonic larvae in the broods of females that grew from non-planktonic larvae at the Step 3 of the experiment (Fig. 7(b)). The mean ratios of non-planktonic larvae in a brood were $16.7 \%$ and $12.2 \%$ in the smallest brood groups of less than 50 eggs and 50 to 99 eggs, respectively, while only $2.5 \%$ of nonplanktonic larvae were found in the large broods over 200 eggs. No statistical significance was found between them (Kruskal-Wallis test, $p>0.05$ ).

Thus, from the results of this study, we conclude that no genetic races with different larval growth sched- (a)

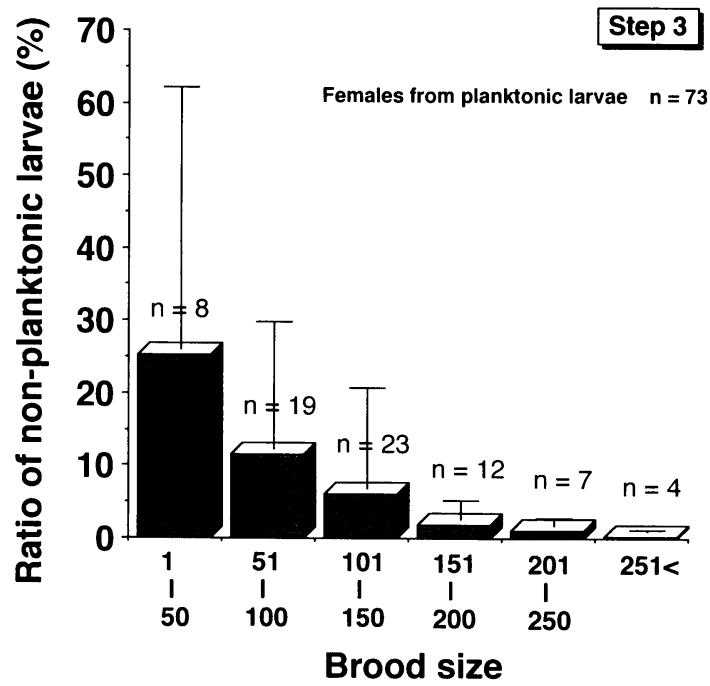

(b)

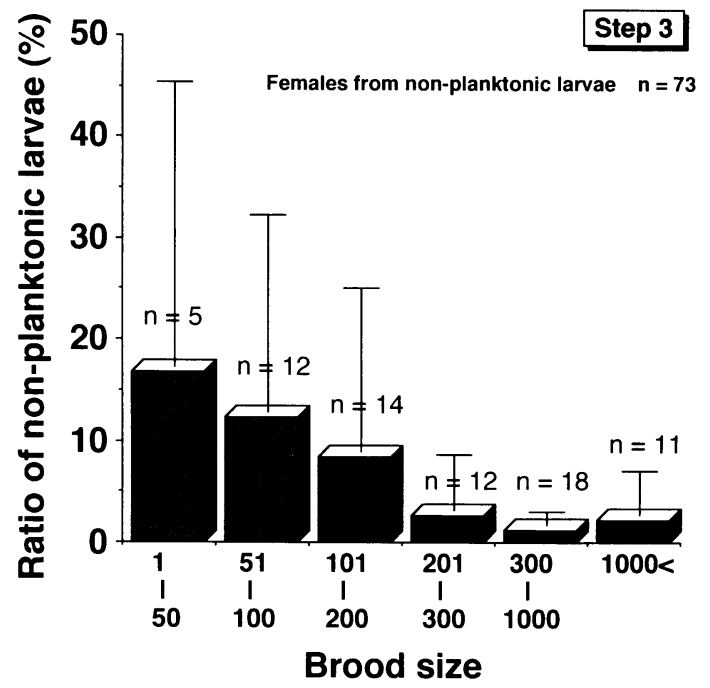

Fig. 7. Mean ratios of non-planktonic larvae in a brood of the females from (a) planktonic larvae and (b) non-planktonic larvae at intervals of 50 brood size at Step 3 of the experiment.

ules are recognized within a single species of Capitella sp. I. A number of mechanisms closely associated with nutritional conditions for the females control the phenotypic plasticity of the larval hatching behaviors.

\section{DISCUSSION}

One of the most distinct characteristics of the population dynamics of Capitella species is opportunistic response to catastrophic environmental disturbance. It was first recorded in the benthic recovery process after an oil spill in the coastal areas in Massachusetts, U.S. in 1969 (Grassle \& Grassle 1974). A Capitella species quickly 
recolonized to the areas where the benthic communities were seriously damaged by the oil pollution, exhibited an explosive population growth, established dense patches over one million individuals per square meter, and declined rapidly as the other benthic fauna recovered. Through genetic analysis of the Capitella populations with isozyme compositions, Grassle \& Grassle (1974) associated the opportunistic population dynamics of Capitella with short term selection of two different genetic races that produced either planktonic larvae with widespread dispersal ability or benthic larvae that are advantageous for rapid population growth in patchy open habitats due to restriction of larval dispersal. However, the Capitella species with variety of isozyme compositions were actually divided into various sibling species with very similar adult morphologies and distinct reproductive modes and larval morphologies (Grassle \& Grassle 1976). Therefore, the opportunistic response of the Capitella species to the environmental disturbance due to the oil spill was conducted by multiple sibling species of Capitella.

The opportunistic population dynamics of Capitella species, however, also can be realized even by a single species of Capitella with uniform life history, reproductive modes and larval morphology. In some organically enriched areas in Japanese coasts where the benthic communities were often suffered from the occurrence of dissolved oxygen deficiency of the bottom water and development of reduced conditions of the sediments, the Capitella species was one of the first recolonizers in the benthic recovery process in the azoic areas and increased very rapidly after recolonization (Tsutsumi \& Kikuchi 1983; Tsutsumi 1987, 1990; Tsutsumi et al. 1990; Ueda et al. 1994).

As shown in this study, females of Capitella sp. I produce both planktonic and non-planktonic larvae from the same brood. Since most of the planktonic larvae settle on the sediment within several hours (Tsutsumi \& Kikuchi 1984), the dispersal range during larval period must be fairly restricted in this species, even if they produced planktonic larvae. Nevertheless, Capitella sp. I is able to exhibit most early recolonization to the disturbed habitats (Tsutsumi \& Kikuchi 1983; Tsutsumi et al. 1991; Tsutsumi 1995). Tsutsumi (1990) revealed the mechanisms of population persistence of Capitella sp. I on a mud flat with disturbed environments due to organic discharge from a sea lettuce bed on the flat. The Capitella species tended to establish dense colonies over $40,000 \mathrm{indi} . / \mathrm{m}^{2}$ in the organically enriched areas on the flat during the cold seasons. From summer to early autumn as the reduced conditions developed in the organi- cally enriched sediments below the sea lettuce bed, the dense patches of Capitella disappeared, but tiny remnant patches remained with extremely low densities of less than $200 \mathrm{ind} . / \mathrm{m}^{2}$ only at the fringe of the sea lettuce bed, where the sediments were sparsely covered by sea lettuce. The remnant patches were only 20 to $40 \mathrm{~m}$ apart from the center of the sea lettuce bed with the most organically enriched sediments. The Capitella species, therefore, did not require a widespread dispersal ability during the larval period to recolonize to the center of the sea lettuce bed, when the sediments became accessible from late autumn. Since the Capitella species can complete its life cycle in only 4 to 6 weeks (Tsutsumi \& Kikuchi 1984) and its potential for population growth is extraordinarily large (cf. Grassle \& Grassle 1974), it could again reestablish dense patches at the center of the sea lettuce bed on the flat by December. Thus, the Capitella species can maintain its population within a single habitat, utilizing the small scale of heterogeneity of environmental conditions and relying on its large potential for population growth.

The results of this study provide an interesting interpretation of the reproductive strategy of Capitella sp. I for population persistence in the disturbed environments caused by organic enrichment of the sediment. As shown in Fig. 5, it is noteworthy that females always produced 2 to 8 individuals of non-planktonic larvae from a single brood, irrespective of the brood size. If the accessible habitats for the Capitella species were restricted in extremely narrow areas with less organically enriched sediment during the summer, and it suffered from decrease of brood size due to the restriction of utilization of organically enriched sediment with ample food resources, the reproductive characteristics of this species producing non-planktonic larvae could ensure the maintenance of a minimum number of recruits beside the adults within the remnant patches.

On the other hand, from late autumn to winter, the Capitella species was allowed to access the organically enriched sediment due to formation of oxidized conditions in the surface layers, and tended to establish extremely dense patches in the organically enriched areas during the cold seasons in Japan (Tsutsumi \& Kikuchi 1983; Tsutsumi 1987, 1990; Yokoyama et al. 1997). The females often could grow up to large body sizes that produced several hundreds of embryo in a brood tube, exploiting the ample food resources of the organically enriched sediment. Here, if we assumed that the body sizes of the females were 0.8 to $1.0 \mathrm{~mm}$ in maximum width of the thoracic segments and the mean ratios of non-planktonic larvae in a brood tube were $2.5 \%$, they would pro- 
duce 145 to 223 individuals of larvae according to the equation expressing the relationship between the body size and brood size in Fig. 2, including 4 to 6 individuals of non-planktonic larvae. During the winter, from each dense patches with large females, enormous number of planktonic larvae would be released to expand its distribution outside its habitats, while they could keep several individuals from each brood for persistence of their patches as extremely small remnant patches during the summer.

In theoretical discussions of reproductive strategy in habitats with disturbed environments, having a period of diapers (or dormancy) or dispersing to new habitats has been emphasized as an advantageous life history trait to avoid the negative impact from the environmental deterioration (Grassle \& Grassle 1974; Sterns 1976). However, the life history with diapers or dormancy has not evolved in the polychaetes, probably due to various biological and physiological constraints. We also need to consider the seasonal fluctuations of the environmental conditions of the habitats with organically enriched sediment that the Capitella species favors and the changeable reproductive output depending on the individual body size.

During the summer, even if Capitella provided "planktonic larvae" outside the habitats to escape from the environmental disturbance, very few open habitats would be available for the larvae due to the development of reduced conditions in the organically enriched sediment in this study area. Furthermore, the number of larvae that can be produced from the summer remnant patches tends to be extremely restricted due to small brood sizes and extremely low densities. The production of "non-planktonic larvae", therefore, seems to be more advantageous for Capitella to minimize the larval loss from the small broods and to ensure sufficient recruits to sustain the tiny remnant patches during summer.

From late autumn to winter, a chance of rapid recovery of population and expansion of distribution comes to Capitella, since the organically enriched sediments are oxidized and the abundant food resources of the sediments become exploitable (cf. Tsutsumi \& Kikuchi 1983; Tsutsumi 1987, 1990). Once even very small numbers of worms succeed in recolonizing from the remnant patches to the adjacent organically enriched areas where the environmental conditions have recovered, the worms are able to grow large adults quickly (within 4 to 8 weeks), the brood sizes of the females increase depending on their growth, production of "planktonic larvae" is enhanced in the large broods, and the planktonic larvae disperse to recolonize to the neighboring open habitats where the larvae can reach during the short pelagic life of less than several hours to one day (Tsutsumi \& Kikuchi 1984; Grassle \& Grassle 1976). Even though the dense patches of the worms disappeared from the organically enriched areas when reduced conditions develop in the sediments again the next summer, the expansion of the distribution and establishment of the dense patches should contribute to leaving small remnant patches somewhere around the dense patches.

Thus, we can explain the adaptive meanings of phenotypic plasticity of larval developmental patterns of Capitella sp. I with a reproductive strategy to persist its population in the highly disturbed habitats by organic enrichment of the sediments.

Acknowledgements. I would like to express my thanks to Dr. Masanori Sato, Ms. Chisa Furudono and Miki Fukuyama for their help in sampling of Capitella sp. I and the experiments, and Dr. Judith P. Grassle and Mr. Richard Lavin for their critical reading of the English text. The photo of non-planktonic larvae of Capitella sp. I was taken by Dr. Masanori Sato. This study was supported by the Research and Development Program for New Bio-industry Initiatives.

\section{REFERENCES}

Chia, F.-S., G. Gibson and P.-Y. Qian 1996. Poecilogony as a reproductive strategy of marine invertebrates. Oceanologica Acta, 19: 203-208.

Eckelbarger, K. J. and J. P. Grassle 1987. Interspecific variation in genital spine, sperm, and larval morphology in six sibling species of Capitella. Biological Society of Washington Bulletin, 7: 62-76.

Forét, J. P. 1974. Étude des effets a long terme de quelques détergents sur la séquence de développement de la polychette sédentaire Capitella capitata (Fabricius). Tethys, 6: 751-778.

Gibson, G. and F.-S. Chia 1995. Developmental variability in the poecilogonous opisthobranch Haminaea callidegenita: Life-history traits and effects of environmental parameters. Marine Ecology Progress Series, 121: 139-155.

Gibson, G. 1997. Variable development in the spionid Boccardia proboscidea (Polychaeta) is linked to nurse egg production and larval trophic mode. Invertebrate Biology, 116: 213-226.

Grassle, J. F. and J. P. Grassle 1974. Opportunistic life histories and genetic systems in marine benthic polychaetes. Journal of Marine Research, 32: 253-284.

Grassle, J. P. and J. F. Grassle 1976. Sibling species in the marine pollution indicator Capitella (Polychaeta). Science, 192: 567-569.

Grassle, J. P. 1980. Polychaete sibling species. In, Aquatic oligochaete biology, Brinkhurst, R. O. and D. G. Cook (eds.), Plenum Publishing Co., New York, pp. 25-32. 
Hoagland, K. E. and R. Robertson 1988. An Assessment of poecilogony in marine invertebrates: phenomenon or fantasy. Biological Bulletin, 174: 109-125.

Levin, L. A. and E. L. Creed 1986. Effect of temperature and food availability on reproductive responses of Streblospio benedicti (Polychaeta: Spionidae) with planktotrophic or lecithotrophic development. Marine Biology, 92: 103-113.

Levin, L. A. and T. S. Bridges 1994. Control and consequences of alternative developmental modes in a poecilogonous polychaete. American Zoology, 34: 323-332.

Levin, L. A., J. Zhu and E. Creed 1991. The genetic basis of life-history characters in a polychaete exhibiting planktotrophy and lecithotrophy. Evolution, 45: 380-397.

Pearson, T. H. and R. Rosenberg 1978. Macrobenthic succession in relation to organic enrichment and pollution of the marine environment. Oceanography and Marine Biology: an Annual Review, 16: 229-311.

Qian, P. Y. and F. S. Chia 1993. Larval development as influenced by food limitation in 2 polychaetes-Capitella sp. I and Polydora ligni Webster. Journal of Experimental Marine Biology and Ecology, 166: 93-105.

Stearns, S. C. 1976. Life-history tactics: a review of the ideas. Quartary Review of Biology, 51: 3-170.

Tsutsumi, H. 1987. Population dynamics of Capitella capitata (Polychaeta; Capitellidae) in an organically polluted cove. Marine Ecology Progress Series, 36: 139-149.

Tsutsumi, H. 1990. Population dynamics of Capitella capitata (Polychaete; Capitellidae) on a mud flat subject to environ- mental disturbance by organic enrichment. Marine Ecology Progress Series, 63: 147-156.

Tsutsumi, H. 1995. Environmental impact of fish net pen culture on bottom of a cove, South Japan. Estuaries, 18: 108115.

Tsutsumi, H. and T. Kikuchi 1983. Benthic ecology of a small cove with seasonal oxygen depletion caused by organic pollution. Publication of Amakusa Marine Biological Laboratory, 7: 17-40.

Tsutsumi, H. and T. Kikuchi 1984. Study of the life history of Capitella capitata (Polychaeta: Capitellidae) in Amakusa, South Japan including a comparison with other geographical regions. Marine Biology, 80: 315-321.

Tsutsumi, H., S. Fukunaga, N. Fujita and M. Sumida 1990. Relationship between Capitella sp. and organic enrichment of the sediment. Marine Ecology Progress Series, 63: 157-162.

Tsutsumi, H., T. Kikuchi, M. Tanaka, T. Higashi, K. Imasaka and M. Miyazaki 1991. Benthic faunal succession in a cove organically polluted by fish farming. Marine Pollution Bulletin, 23: 233-238.

Ueda, N., H. Tsutsumi, M. Yamada, R. Takeuchi and K. Kido 1994. Recovery of the marine bottom environment of a Japanese bay. Marine Pollution Bulletin, 28: 676-682.

Yokoyama, H., K. Abo, M. Toyakawa, S. Toda and S. Yamamoto 1997. Impact of mariculture on the spatial and temporal patterns of the macrobenthos in Gokasho Bay. Bulletin of National Research Institute of Aquaculture, Supplement 3: $7-16$. 